\title{
IDENTIFICATION OF iso(18p) MARKER CHROMOSOME BY FLUORESCENCE IN SITU HYBRIDIZATION WITH SINGLE-COPY DNA PROBE
}

\author{
Hitoshi NaKashima, ${ }^{1}$ Tomoko Hasegawa, ${ }^{2}$ Masako SaKaI, ${ }^{1}$ \\ Rie INABA, ${ }^{1}$ and Takashi Imamura ${ }^{1, *}$ \\ ${ }^{1}$ Department of Human Genetics, National Institute of Genetics, \\ 1111 Yata, Mishima 411, Japan \\ ${ }^{2}$ Department of Pediatrics, Shizuoka Children's Hospital, \\ Shizuoka 420, Japan
}

\begin{abstract}
Summary The patient displayed the clinical features consistent with tetrasomy (18p) syndrome, who had an extra small metacentric iso(18p) chromosome in otherwise normal karyotype. Identification of the marker chromosome used the chromosome 18 band-specific fluorescence in situ hybridization strategy.
\end{abstract}

Key Words fluorescence in situ hybridization (FISH), tetrasomy $18 \mathrm{p}$ syndrome, iso(18p) chromosome

\section{INTRODUCTION}

Many cases of extra marker chromosomes have been reported, including familial and 'de novo' events. In the inherited cases the extra chromosome may not appear to be causally related to the phenotype of the porbands. The de novo cases present a variety of clinical pictures depending on the different origins of the markers. Small marker chromosomes cannot be easily identified using standard cytogenetic banding techniques because they lack a distinct banding pattern. Marker chromosomes may be associated with a wide range of phenotypes, making it important to identify the chromosomal origin of the markers so that correlations with a clinical phenotype can be evaluated (Froland et al., 1963; Lin et al., 1990; Callen et al., 1990; Mewar et al., 1993).

To develop a method that can differentiate between the iso(18p) and other markers including the $18 \mathrm{q}$ - chromosome, cosmid probes were cloned from both arms of chromosome 18 using a somatic cell hybrids, which were then mapped to chromosome 18 by fluorescence in situ hybridization (FISH) (Nakashima et al.,

Received November 2, 1994; Revised version accepted February 8, 1995.

* To whom correspondence should be addressed. 
1993). The probe was labeled with biotin and used to identify rearrangements involving the chromosome 18 . This approach was used to analyze one patient with the phenotype of tetrasomy $(18 \mathrm{p})$.

\section{MATERIALS AND METHODS}

Cytogenetic analysis. The patient is a 15-year-old boy. He has microcephaly, epicanthal folds, hypotelorism, hypotonia, a single simian crease, and mildly delayed development. Chromosomes were prepared from peripheral lymphocytes (PBLs) and the karyotype was analyzed by the standard GTG-banding procedure. To induce R-banding stimulated PBLs were synchronized by blocking the cell cycle for $16 \mathrm{~h}$ with excess thymidine, and were treated with 5-bromo-2'-deoxyuridine (BrdU) during the final late S-phase before harvesting (Viegus-Pequignot and Dutrillaux, 1978). For R-banding and FISH analysis, chromosome spreads were stained with Hoechst 33258 and were exposed to UV light for $10 \mathrm{~min}$ (Takahashi et al., 1991). To induce multiple 4',6-diamino-2-phenylindole (DAPI)-banding, denaturation time was shortened to $30-60 \mathrm{sec}$ as described (Heng and Tsui, 1993), and the step of UV exposure was omitted.

Fluorescence in situ hybridization (FISH). A set of chromosome 18-specific DNA probes were obtained from a cosmid DNA library derived from the cell line MS126, a somatic cell hybrid containing a normal chromosome 18 as its only human component (Nakashima et al., 1993). Cosmid SCW0204F was hybridized specifically to the short arm at $18 \mathrm{p} 11.2$, and SCW0207A hybridized to the pericentric region of chromosome 18 .

FISH was performed according to the methods described elsewhere (Lichter et al., 1988; Takahashi et al., 1991). Cosmid DNAs were labeled by nick translation using the enzyme kit (Boehringer Mannheim, GmbH) with biotin-11-dUTP (Boehringer Mannheim) and hybridized to chromosome DNA under conditions that suppress signals from repetitive sequences (Lichter et al., 1988). Hybridization signals were localized to a specific chromosome region either by simultaneous Rbanding or by DAPI-banding analysis of the same metaphase spread. Hybridized probes were detected by means of fluorescein isothiocyanate (FITC) conjugated to avidin (Vector Laboratory, CA). Fluorescent signals were amplified with biotinylated anti-avidin antibody (Vector Laboratories) (Pinkel et al., 1988). Signals on both metaphase and interphase nuclei were viewed using a Zeiss Axiophot epifluorescence microscope (Carl Zeiss Mikroskop-System, Germany) equipped with a cooled Charge Coupled Device (CCD) camera (Astromed, Cambridge, England).

\section{RESULTS}

Chromosome analyses revealed a karyotype, 47,XY,+mar, for nearly all cells examined. The marker chromosome was metacentric and potentially an iso(18p). A probe previously localized on the short arm of chromosome 18 was selected for 


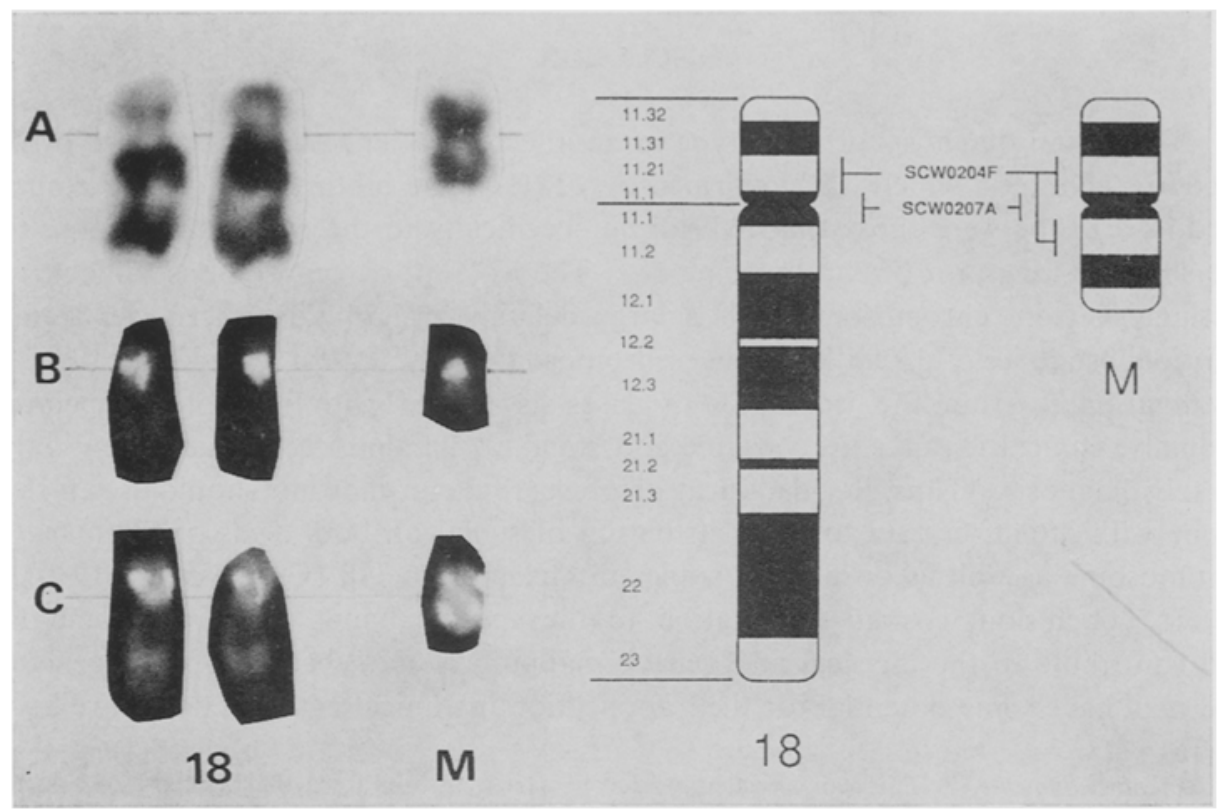

Fig. 1. Three partial metaphases showing the specific site of probe hybridization. A: G-banding partial karyotype showing the normal copies of chromosome 18 and a marker chromosome (M). B: Fluorescent signals of a cosmid probe SCW0207A on the pericentric region, obtained by R-banding and FISH. C: Fluorescent signals of the probe SCW0204F on the short arm at 18p11.2, obtained by DAPIbanding and FISH. Duplicated signals of the probe are observed on both arms of an iso(18p) marker chromosome.

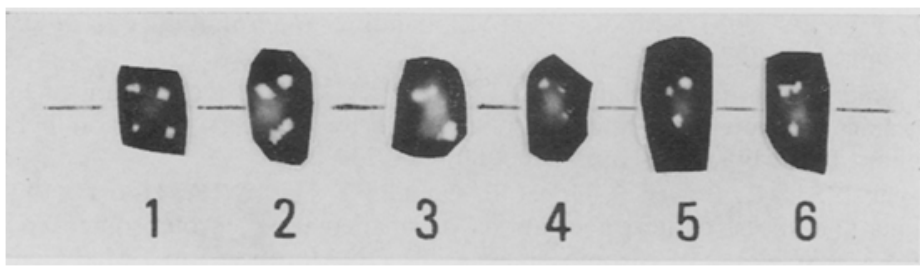

Fig. 2. Small metacentric marker chromosomes from 6 cells of a patient with tetrasomy $18 \mathrm{p}$ syndrome. Duplicated fluorescence signals of a cosmid SCW0204F are observed on both arms of an iso(18p) chromosome.

FISH to determine origin of the marker chromosome. Fluorescent signal of the probe SCW0204F DNA was present on the short arm at $18 \mathrm{p} 11.2$ of the normal copies of chromosome 18 (Fig. 1). Furthermore, the probe was hybridized to both arms of the metacentric marker chromosome (Figs. 1c and 2). The results clearly indicate that the marker chromosome is the iso(18p). Parental chromosome studies were not carried out. 


\section{DISCUSSION}

Our initial diagnosis of karyotype in an affected patient was by standard cytogenetic techniques, which was confirmed by FISH. The biotinylated cosmid clones used as a probe were those that hybridized specifically to the pericentric region, to the short or long arm of chromosome 18. The iso(18p) chromosome is difficult to distinguish from chromosome with a large deletion of 18q. Furthermore, translocation products of 18 with another chromosome may appear cytogenetically indistinguishable from the iso(18p). In cases associated with multiple congenital anomaly, clinical features are variable and standard banding techniques allow only a likely diagnosis. Thus, the identification of iso( $18 \mathrm{p}$ ) chromosome should use an $18 \mathrm{p}$ probe with attention paid to the distribution of signal on both arms of the marker chromosome as well as on normal copies of chromosome 18 (Callen et al., 1990).

In conclusion, cosmid localization to the specific bands of chromosome 18 will contribute to the physical and genetic mapping of this chromosome in general and may have some potential for their application in clinical cytogenetics as well.

Acknowledgments This work was supported in part by grants from the Ministry of Education, Science and Culture, and by grants from the Ministry of Health and Welfare of Japan.

\section{REFERENCES}

Callen DF, Freemantle CJ, Ringenbergs ML, Baker E, Eyre HJ, Romein D, Haan EA (1990): The isochromosome 18p syndrome: conformation of cytogenetic diagnosis in nine cases by in situ hybridization. Am J Hum Genet 47: 493-498

Froland A, Holst G, Terslev E (1963): Multiple anomalies associated with an additional small metacentric chromosome. Cytogenetics 2: 99-106

Heng HHQ, Tsui LC (1993): Modes of DAPI banding and simultaneous in situ hybridization. Chromosoma 102: 325-332

Lichter P, Cremer T, Borden J, Manuelidis L, Ward DC (1988): Delineation of individual human chromosomes in metaphase and interphase cells by in situ suppression bybridization using recombinant DNA libraries. Hum Genet 80: 224-234

Lin CC, Meyne J, Sasi R, Bowen P, Unger T, Tainaka T, Hadro TA, Hoo JJ (1990): Determining the origins and the structural aberrations of small marker chromosome $18 \mathrm{p}$ in two cases of $45, X / 46, X,+$ mar by use of chromosome-specific DNA probes. Am J Med Genet 37: 71-78

Mewar R, Harrison W, Overhauser J (1993): Conformation of isochromosome 18p using whole chromosome arm-specific fluorescence in situ hybridization. Cytogenet Cell Genet 64: 1-4

Nakashima H, Sakai M, Inaba R, Imamura T (1993): Isolation and fluorescence in situ hybridization (FISH) mapping of 60 cosmid clones on the human chromosome 18. Genomics 19: 577580

Pinkel D, Landegent J, Collins C, Fuscoe J, Segraves R, Lucas J, Gray $\mathbf{J}$ (1988): Fluorescence in situ hybridization with human chromosome-specific libraries: detection of trisomy 21 and translocations of chromosome 4. Proc Natl Acad Sci USA 85: 9138-9142

Takahashi E-I, Yamauchi M, Tsuji H, Hitomi A, Meuth M, Hori T-A (1991): Chromosome mapping of the human cytidine-5'-triphosphate synthetase (CTPS) gene to band 1p34.1-p34.3 by fluorescence in situ hybridization. Hum Genet 88: 119-121

Viegas-Pequignot E, Dutrillaux B (1978); Une methode simple pour obtenir des prophases et des prometaphases. Ann Genet (Paris) 21: 122-125

Jpn $J$ Human Genet 